\title{
Unusual Mass Spectrometric Dissociation Pathway of Protonated Isoquinoline-3-Carboxamides Due to Multiple Reversible Water Adduct Formation in the Gas Phase
}

\author{
Simon Beuck, ${ }^{\text {a }}$ Tobias Schwabe, ${ }^{\mathrm{b}}$ Stefan Grimme, ${ }^{\mathrm{b}}$ Nils Schlörer, ${ }^{\mathrm{c}}$ \\ Matthias Kamber, ${ }^{d}$ Wilhelm Schänzer, ${ }^{a}$ and Mario Thevis ${ }^{a}$ \\ a Center for Preventive Doping Research, Institute of Biochemistry, German Sport University Cologne, \\ Cologne, Germany

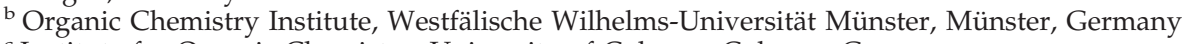 \\ c Institute for Organic Chemistry, University of Cologne, Cologne, Germany \\ d Antidoping Switzerland, Berne, Switzerland
}

\begin{abstract}
The study of the collision-induced dissociation behavior of various substituted isoquinoline3 -carboxamides, which are amongst a group of drug candidates for the treatment of anemic disorders (e.g., FG-2216), allowed for the formulation of the general mechanisms underlying the unusual fragmentation behavior of this class of compounds. Characterization was achieved with high-resolution/high accuracy LTQ-Orbitrap tandem mass spectrometry of the protonated precursor ions. Presented data were substantiated by the synthesis and analysis of proposed gas-phase intermediate structures and stable isotope labeled analogues, as well as by density functional theory calculations. Exemplary, CID of protonated N-[(1-chloro4-hydroxy-7-isopropoxy-isoquinolin-3-yl)carbonyl]glycine gives rise to the isoquinoline-3carboxy-methyleneamide product ion which nominally eliminates a fragment of $11 \mathrm{u}$. This was attributed to the loss of methyleneamine $(-29 \mathrm{u})$ and a concomitant spontaneous and reversible water addition $(+18 \mathrm{u})$ to the resulting acylium ion to yield the protonated isoquinoline-3-carboxylic acid. The same water addition pattern is observed after loss of propylene $(-42 \mathrm{u})$. A further nominal loss of $10 \mathrm{u}$ is explained by the elimination of carbon monoxide $(-28 \mathrm{u})$ followed by another water adduct formation $(+18 \mathrm{u})$ to yield the protonated 1-chloro-3,4,7-trihydroxy-isoquinoline. The source of the multiple gas-phase water addition remained unclear. This atypical fragmentation pattern proved to be highly characteristic for all studied and differentially substituted isoquinoline-3-carboxamides, and offers powerful analytical tools for the establishment of a LC/MS(/MS) based screening procedure for model HIF-stabilizers and their potential metabolites in clinical, forensic and sports drug testing. (J Am Soc Mass Spectrom 2009, 20, 2034-2048) (c 2009 American Society for Mass Spectrometry
\end{abstract}

$\mathrm{T}$ The transcriptional activator HIF (hypoxia-inducible factor) is a central mediator in the concert of cellular responses to deficient oxygen supply in aerobic organisms [1] and its regulation has become an important pivot point for the pharmacological treatment of anemic diseases such as chronic kidney disease (CKD) [2]. In normoxia, post-translational hydroxylation of two distinct proline residues in the oxygendependent degradation domain of HIF $\alpha$ induces its rapid proteasomal degradation. Under hypoxic conditions, the proline modification is suppressed, consequently leading to HIF-stabilization and transcription of genes for hypoxia compensating processes, such as angiogenesis, erythropoiesis, and glucose metabolism

Address reprint requests to Dr. M. Thevis, Center for Preventive Doping Research, Institute of Biochemistry, German Sport University Cologne, Am Sportpark Muengersdorf 6, 50933 Cologne, Germany. E-mail: thevis@dshskoeln.de
[3]. Members of a conserved family of 2-oxoglutarate and iron dependent enzymes, the prolyl hydroxylase domain proteins (PHD), specifically catalyze the hydroxylation of HIF-prolyl residues in an oxygen dependent manner, thus playing the pivotal role in molecular oxygen sensing [4-6]. Various substances with the capacity to inhibit PHD activity (prolyl hydroxylase inhibitors, PHI) have been identified and analyzed concerning their ability to induce the erythropoietic cascade by HIF-stabilization [7, 8]; in this context, substituted isoquinoline-3-carboxamides belong to the most promising class of compounds regarding potential clinical applications [9, 10]. The lead drug candidate FG-2216 (Fibrogen and Astellas) is an orally available anti-anemia agent that was shown to significantly raise blood hemoglobin $(\mathrm{Hb})$ levels in CKD patients in recent phase II clinical trials [11, 12]. Remarkably, for the low dosage cohort a significant $\mathrm{Hb}$-rise was observed de- 
spite only modest elevation of plasma erythropoietin (Epo) levels, indicating the stimulation of the complete erythropoietic machinery, including increased expression of genes for red blood cell maturation and enhanced iron metabolism (e.g., Epo receptor, transferrin and its receptor, ferroprotein, and the divalent metal transporter 1) [13]. After one case of death by fulminant hepatitis caused a clinical hold of the phase II trial of FG-2216, the FDA permitted to resume the clinical testing in April 2008 [14, 15].

Since this novel compound class is capable of enhancing the organism's capacity for molecular oxygen transport, it also possesses great potential for abuse as performance enhancing agent in sports. In the course of preventive doping research, it is vital to timely identify and characterize such substances, even before they enter the open market as approved drug. In recent mass spectrometric studies of a model $\mathrm{PHI}$ with isoquinoline3-carboxamide core, first fundamental data for the development of analytical methods for HIF-stabilizing potential drugs were presented [10]. An unusual dissociation behavior was discovered that included a nominal loss of $11 \mathrm{u}$ and the association of neutral molecules to gas-phase ions. Such clustering reactions have been observed earlier in several mass spectrometric studies [1618]. In particular, acylium fragment ions were shown to readily undergo specific gas-phase ion-molecule reactions [19], or associate with solvent molecules such as water to complicate the interpretation of resulting product ion mass spectra [20]. To further elucidate the phenomena occurring during mass spectrometric fragmentation of isoquinoline-3-carboxamides, we studied the collision induced dissociation (CID) behavior of structurally related model HIF-stabilizers build on the same isoquinoline scaffold. The results from electrospray ionization highresolution/high accuracy ion trap/Orbitrap mass spectrometry were augmented by the synthesis and analysis of stable isotope labeled analogues and proposed gasphase intermediate structures. Moreover they were substantiated by density functional theory calculations, yielding proton affinities and reaction energies of a postulated fragmentation pathway. We propose a general dissociation mechanism for isoquinoline-3-carboxamides, explaining unusual nominal losses of 10 and $11 \mathrm{u}$ by reversible water adduct formation of gas-phase fragment ions at numerous stages.

The dissociation behavior is shown to be highly characteristic for isoquinoline-3-carboxamides and constitutes a fundament upon which powerful analytical tools for the screening for orally available HIF-stabilizers and their metabolites may be developed for clinical, forensic, and sports drug testing.

\section{Experimental}

\section{Chemicals and Reagents}

Ethanol, methanol, ethyl acetate, petroleum ether, $n$-heptane, diethyl ether, silica gel 60 (70-230 mesh), hydrochloric acid
(36\% aqueous solution, wt/wt), sulfuric acid (98\%,wt/wt) (all analytical grade), and ethanolamine (synthesis grade) were purchased from Merck (Darmstadt, Germany), dichloromethane, 1-butanol, Dowtherm A (eutectic mixture of $26.5 \%$ of diphenyl and $73.5 \%$ of diphenyl oxide), $N, N-$ dimethylacetamide (all analytical grade), dimethylsulfoxide$d_{6}$, acetone- $d_{6}$, chloroform- $d$, methanol- $d$, deuterium oxide (all 99.9 atom \%), glycine- $d_{5}$ (98 atom \%), glycine (98\%), sodium, sodium hydroxide $(99 \%)$, palladium $(10 \%$ on active charcoal), triethylamine (99\%), N,N-diisopropylethylamine (99\%), benzotriazole-1-yl-oxy-tris-pyrrolidino-phosphonium hexafluorophosphate (98\%), glycine methyl ester hydrochloride (99\%, and [1-(chlorophenyl)-N-methyl-N(-1-methylpropyl)-3-isoquinoline carboxamide] were obtained from Sigma (Deisendorf, Germany). 4Hydroxyphthalic acid (98\%), 2-iodopropane (98\%), potassium carbonate (99\%), potassium hydroxide (99\%), and phosphorous oxychloride (99\%) were from Acros (Geel, Belgium). Dihydrogen (technical grade 3.0) and nitrogen gas (purity grade 5.0) were obtained from Linde (Duesseldorf, Germany).

\section{Synthesis of Model Compounds}

Four model PHIs and related compounds were synthesized in accordance to methods described elsewhere [21]. Briefly, 4-hydroxyphthalic acid (Scheme 1a) was converted into the diethylester and alkylated with 2iodopropane, to yield 4-(2-propyloxy)phthalic acid diethyl ester, which liberated 4-(2-propyloxy)phthalic acid (Scheme $\mathbf{1 b}$ ) upon saponification. Reaction of $\mathbf{b}$ with equimolar amount of glycine in Dowtherm at $200{ }^{\circ} \mathrm{C}$ gave rise to 4-(2-propyloxy)phthaloyl)iminoacetic acid, which was esterified with 1-butanol and hydrochloric acid. The 5-membered heterocycle of the resulting phthaloyliminoacetic acid 1-butyl ester (Scheme 1c) was extended by treatment with 0.5 eq of sodium butanolate at $95{ }^{\circ} \mathrm{C}$ to yield 4-hydroxy-7-(2propyloxy)-1(2H)-isoquinolone-3-carboxy-(1-butyl) ester (Scheme 2, isomer $\mathbf{d}$ ) and the 6-(2-propyloxy) isomer e (Scheme 1) in a 1:2 ratio. The two isomers were separated by fractionized crystallization, purified by column chromatography (ethyl acetate on silica gel, $R_{f}(d)$ : $\left.0.5 ; R_{f}(\mathbf{e}): 0.35\right)$, and separately processed. Isomer $\mathbf{d}$ was refluxed in phosphorous oxychloride to yield 1-chloro-4hydroxy-7-(2-propyloxy)isoquinoline-3-carboxy-(1-butyl)ester, which liberated the free carboxylic acid 5 (Figure 1, Scheme 1) by alkaline hydrolysis. Amide bond formation by reaction with glycine methyl ester hydrochloride and benzotriazole-1-yl-oxy-tris-pyrrolidino-phosphonium hexafluorophosphate as coupling agent gave rise to the isoquinoline-(3-carboxy)glycine amide methyl ester, which was purified by flash chromatography using ethyl acetate/ $n$-heptane (1:3, vol/vol) on silica gel. Pure target Compound 1 (Figure 1, Scheme 1) was obtained by alkaline hydrolysis of the purified methyl ester. 
(a)

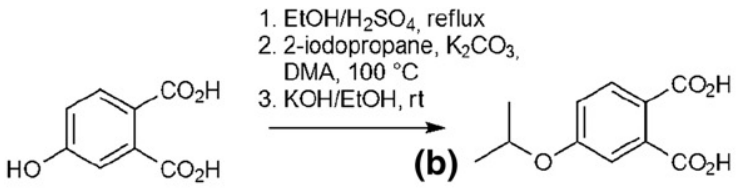

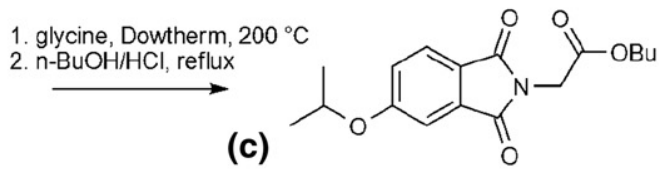

(e)<smiles>CCOC(=O)c1[nH]c(=O)c2ccc(OC(C)C)cc2c1O</smiles>

1. $\mathrm{POCl}_{3}$, reflux

2. $\mathrm{NaOH} / \mathrm{EtOH}$, reflux

1. glycine methyl ester $\mathrm{HCl}$, PyBOP, $\mathrm{Et}_{3} \mathrm{~N},(\mathrm{iPr})_{2} \mathrm{EtN}, \mathrm{rt}$ 2. $\mathrm{NaOH} / \mathrm{MeOH}, \mathrm{rt}$<smiles>CC(C)Oc1ccc2c(O)c(C(=O)O)nc(Cl)c2c1</smiles>

5 1. $\mathrm{H}_{2} / \mathrm{Pd} / \mathrm{C}, \mathrm{rt}$
2. glycine methyl ester $\mathrm{HCl}$,
$\mathrm{PyBOP}, \mathrm{Et}_{3} \mathrm{~N},(\mathrm{iPr})_{2} \mathrm{EtN}$, it
3. $\mathrm{NaOH} / \mathrm{MeOH}, \mathrm{rt}$<smiles>CC(C)Oc1ccc2c(O)c(C(=O)NCC(=O)O)nc(Cl)c2c1</smiles><smiles>CC(C)Oc1ccc2c(O)c(C(=O)NCC(=O)O)ncc2c1</smiles>

1 3<smiles>CCOC(=O)c1nc(Cl)c2ccc(OC(C)C)cc2c1O</smiles>
ethanolamine, $85^{\circ} \mathrm{C}$

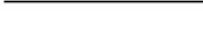

(f)<smiles>CC(C)Oc1ccc2c(Cl)nc(C(=O)NCC(=O)O)c(O)c2c1</smiles>

2<smiles>[2H]C([2H])(NC(=O)c1nc(Cl)c2cc(OC(C)C)ccc2c1O)C(=O)O</smiles>

(g)

6

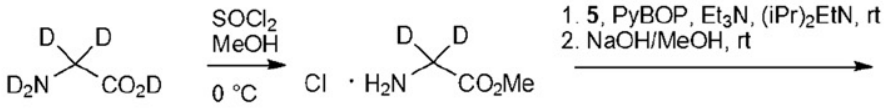

Scheme 1. Route of synthesis of drug candidate molecules and related compounds.
Compound 2 (Figure 1, Scheme 1) was synthesized and purified from Compound $\mathbf{e}$ in analogy to the synthesis of $\mathbf{1}$. Moreover, dehalogenation of Compound 5 by hydrogenation with palladium/active charcoal as catalyst and subsequent glycine amide bond formation allowed for the preparation of Compound 3 (Figure 1, Scheme $\mathbf{1})$. Reaction of Compound $\mathbf{f}$ with ethanolamine yielded Compound 4 (Figure 1, Scheme 1), which was crystallized from ethyl acetate $/ n$-heptane. An isotope labeled analogue bearing two deuterium atoms in the glycine residue (Compound 6, Figure 1, Scheme 1) was synthesized by amide bond formation between $d_{2}-$ labeled glycine methyl ester hydrochloride (Scheme 1g) and Compound 5. All structures were confirmed by high field nuclear magnetic resonance spectroscopy (NMR) with ${ }^{1} \mathrm{H}(600 \mathrm{MHz}), \mathrm{H}, \mathrm{H}-\mathrm{COSY}, \mathrm{H}, \mathrm{C}-$ HMQC, H,C-HMBC, and ${ }^{13} \mathrm{C}$ APT (150 MHz) experiments employing a Bruker AV 600 instrument (Bruker, Karlsruhe, Germany) equipped with a $5 \mathrm{~mm}$ inverse probe head (z-gradient coil). The spectra were recorded at room temperature from solutions of $\mathbf{1}, \mathbf{2}$, and 3 in dimethylsulfoxide- $d_{6}, 4$ in chloroform- $d$, and 5 and 6 in acetone- $d_{6}$, respectively (all $\sim 10 \mathrm{mg} / \mathrm{mL}$ ), and calibrated using the solvent residual peak as reference signal. Additionally, the elemental compositions of the synthesized substances were determined using high-resolution/high accuracy mass spectrometry utilizing a LTQ Orbitrap (Thermo, Bre- 

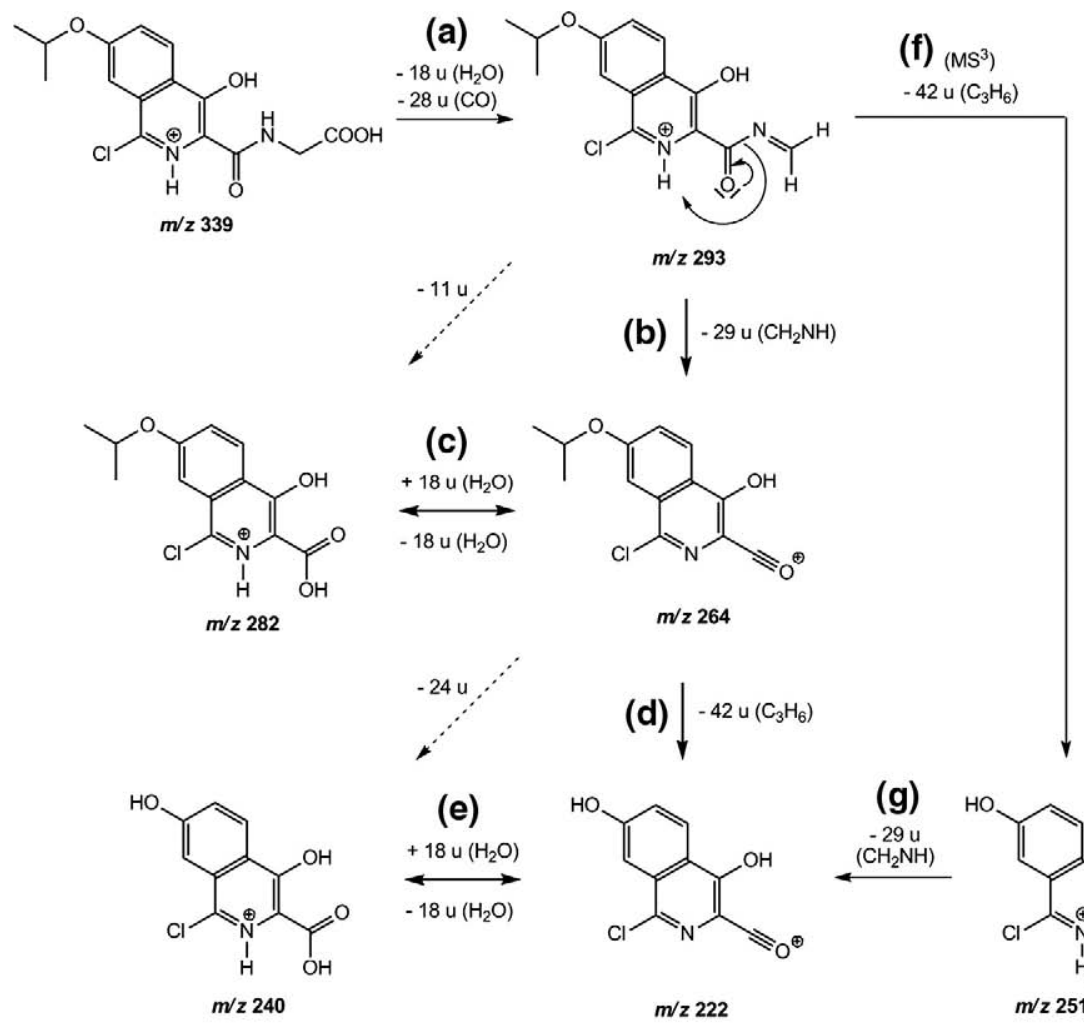

(e)
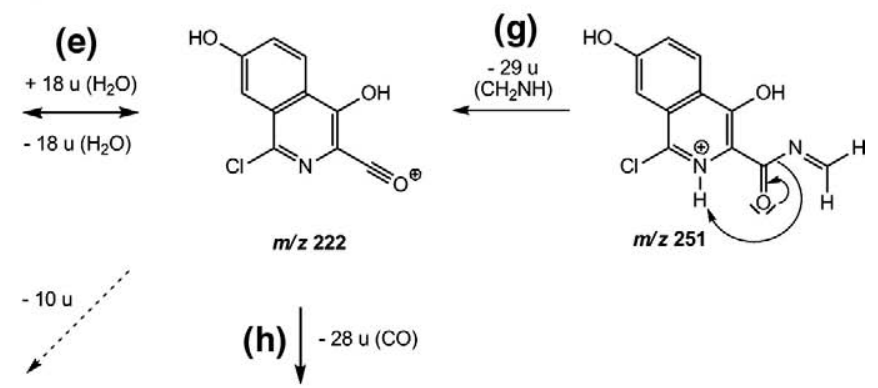

(h) $\downarrow-28 \mathrm{u}(\mathrm{CO})$
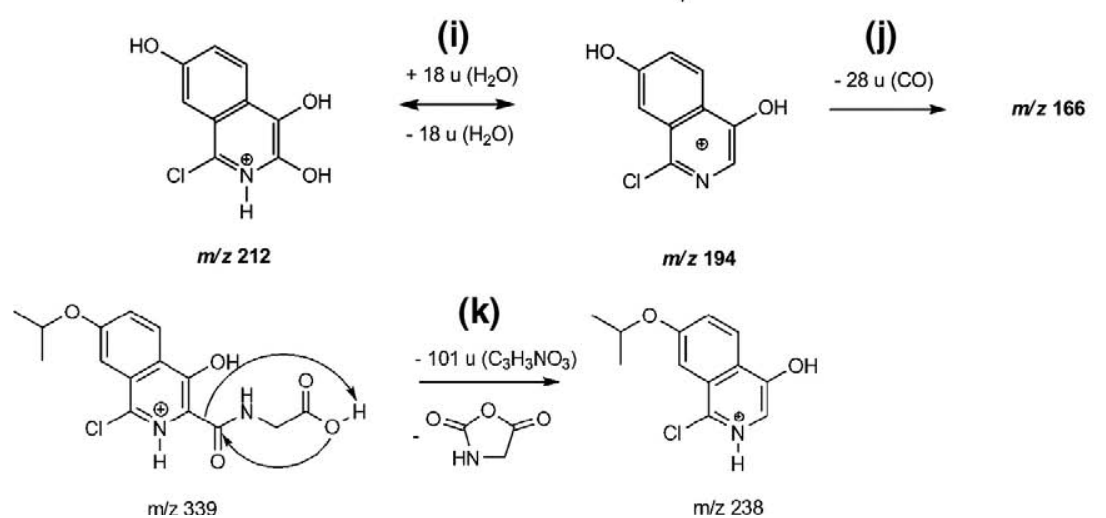

Scheme 2. Proposed dissociation pathways of protonated drug candidate 1

men, Germany) at a resolving power of 30,000 (FWHM).

\section{Electrospray Ionization-Tandem Mass Spectrometry}

ESI-MS(/MS) experiments were conducted on a LTQ Orbitrap mass spectrometer. Spectra were recorded in positive ionization mode after calibration was achieved with the manufacturer's calibration mixture (containing caffeine, MRFA, and Ultramark). Mass accuracies $<5$ ppm (calculated from 30 averaged spectra) were monitored and accomplished for the period of analysis. Analytes were dissolved in acetonitrile/water (1:1, vol/vol) containing $0.5 \%$ of formic acid at concentrations of 10 $\mu \mathrm{g} / \mathrm{mL}$ and introduced into the ion source of the mass spectrometer with a syringe pump at a flow rate of 5 $\mu \mathrm{L} / \mathrm{min}$. The ionization voltage was set to $4200 \mathrm{~V}$, the capillary temperature was $275^{\circ} \mathrm{C}$, and for MS ${ }^{n}$ experiments the precursor ions were isolated with a width of 1.5 $\mathrm{Da}$. The protonated species were dissociated at normalized collision energies between 12 and 30 arbitrary units (Xcalibur software version 2.0; Thermo, Bremen, Germany). Damping and collision gas in the linear ion trap was helium (purity grade 5.0), while nitrogen, obtained from a CMC nitrogen generator (CMC Instruments, Eschborn, Germany), was used for the curved linear ion trap (CLT). In addition to the Orbitrap experiments, ESI-MS(/ 


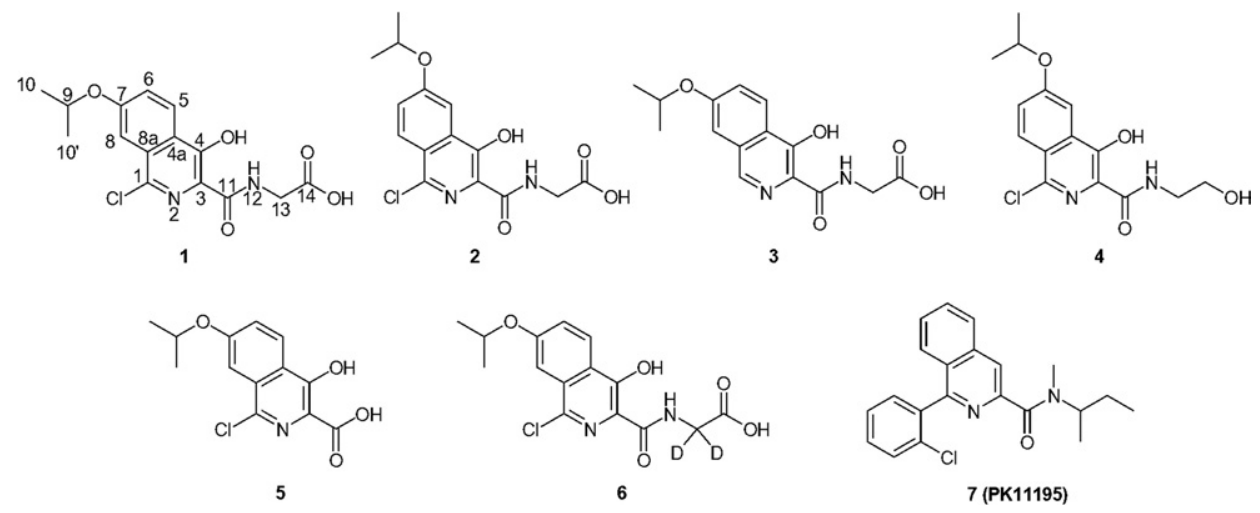

Figure 1. Molecular structures of studied compounds: drug candidates (1) N-[(1-chloro-4-hydroxy7-isopropoxy-isoquinolin-3-yl)carbonyl]glycine, atom numbers for NMR characterization are shown exemplary for all related structures; (2) N-[(1-chloro-4-hydroxy-6-isopropoxy-isoquinolin-3-yl)carbonyl] glycine; (3)N-[(4-hydroxy-7-isopropoxy-isoquinolin-3-yl)carbonyl]glycine; (4) 1-chloro-4-hydroxy-6isopropoxy-isoquinolin-3-carboxylic-acid-N-(2-hydroxyethyl)amide; (5) putative gas-phase intermediate structure 1-chloro-4-hydroxy-7-isopropoxy-isoquinolin-3-carboxylic acid; (6) stable isotope labeled drug candidate 1; (7) [1-(chlorophenyl)-N-methyl-N-(-1-methylpropyl)-3-isoquinoline carboxamide] (PET-tracer PK11195).

MS) studies were performed using an Applied Biosystems API 2000 QTrap mass spectrometer (Darmstadt, Germany) with electrospray ionization and direct infusion of the analyte working solutions (vide supra) to examine potential instrument-dependent differences in fragmentation pathways. Nitrogen was employed as curtain and collision gas $\left(5 \times 10^{-3} \mathrm{~Pa}\right)$ delivered from a CMC nitrogen generator (CMC Instruments, Eschborn, Germany), and collision offset voltages or nozzle-skimmer dissociation settings were optimized for each experiment.

\section{Density Functional Theory Calculations}

All molecular structures are fully optimized and are obtained at the PBE [22]/def2-TZVP [23] level of theory as well as the molecular and reaction energies are. The resolution-of-identity (RI) approximation (also called density-fitting) for the two-electron Coulomb interactions has been applied to speed up the calculations. The corresponding optimized auxiliary basis sets [24] have been taken from the TURBOMOLE libraries and a multiple integration grid (m3) was used [25]. All computations have been carried out with a locally modified version of TURBOMOLE 5.9 [26-28]. Proton affinities are computed as the differences between the total energies of the neutral reactant and the cation without vibrational or thermal contributions. Both are expected to play a minor role especially when relative and not absolute proton affinities are considered. They are also neglected for all other relative energies.

\section{Results and Discussion}

\section{Synthesis and Characterization of Model PHI Compounds}

The synthesis yielded the desired structures with overall yields ranging from $3 \%$ to $6 \%$ providing sufficient amounts of pure analytes for structure characterization (purity estimated from ${ }^{1} \mathrm{H}$ NMR: $95 \%$ to $98 \%$ ). The assignment of atomic numbers for NMR-characterization is shown exemplary in Figure 1. Compound $1,{ }^{1} \mathrm{H}$ NMR (DMSO- $\left.d_{6}\right), \delta: 13.59(\mathrm{~s}, 1 \mathrm{H}, \mathrm{OH}-4), 12.81$ (s, broad, $1 \mathrm{H}), 9.09(\mathrm{t}, \mathrm{J}=6.2 \mathrm{~Hz}, 1 \mathrm{H}, \mathrm{NH}-12), 8.24(\mathrm{~d}, \mathrm{~J}=9.0 \mathrm{~Hz}$, $1 \mathrm{H}, \mathrm{CH}-5), 7.58$ (dd, J = 9.0/2.3 Hz, 1H, CH-6), 7.50 (d, $\mathrm{J}=2.3 \mathrm{~Hz}, 1 \mathrm{H}, \mathrm{CH}-8), 4.92$ (sept, $\mathrm{J}=6.1,1 \mathrm{H}, \mathrm{CH}-9), 4.02$ $\left(\mathrm{d}, \mathrm{J}=6.2 \mathrm{~Hz}, 2 \mathrm{H}, \mathrm{CH}_{2}-13\right), 1.38(\mathrm{~d}, \mathrm{~J}=6.1 \mathrm{~Hz}, 6 \mathrm{H}$, $\left.\mathrm{CH}_{3}-10 / 10^{\prime}\right) ;{ }^{13} \mathrm{C}$ NMR (DMSO-d $\left.d_{6}\right), \delta: 170.77$ (C-14), 169.13 (C-11), 159.85 (C-7), 154.58 (C-4), 137.16 (C-1), 130.84 (C-8a), 125.43 (C-5), 123.82 (C-6), 123.81 (C-4a), 119.24 (C-3), 107.01 (C-8), 70.68 (C-9), 40.90 (C-13), 21.68 (C-10/10').

Compound 2, ${ }^{1} \mathrm{H}$ NMR (DMSO- $\left.d_{6}\right), \delta: 13.59(\mathrm{~s}, 1 \mathrm{H}$, $\mathrm{OH}-4), 12.85$ (s, broad, $1 \mathrm{H}), 9.19(\mathrm{t}, \mathrm{J}=6.2 \mathrm{~Hz}, 1 \mathrm{H}$, $\mathrm{NH}-12), 8.21(\mathrm{~d}, \mathrm{~J}=9.1 \mathrm{~Hz}, 1 \mathrm{H}, \mathrm{CH}-8), 7.59(\mathrm{~d}, \mathrm{~J}=2.3$ $\mathrm{Hz}, 1 \mathrm{H}, \mathrm{CH}-5), 7.56$ (dd, J = 9.1/2.3 Hz, 1H, CH-7), 4.95 (sept, J $=6.0,1 \mathrm{H}, \mathrm{CH}-9), 4.07(\mathrm{~d}, \mathrm{~J}=6.2 \mathrm{~Hz}, 2 \mathrm{H}$, $\left.\mathrm{CH}_{2}-13\right), 1.41\left(\mathrm{~d}, \mathrm{~J}=6.0 \mathrm{~Hz}, 6 \mathrm{H}, \mathrm{CH}_{3}-10 / 10^{\prime}\right) ;{ }^{13} \mathrm{C} \mathrm{NMR}$ (DMSO- $\left.d_{6}\right), \delta: 170.71$ (C-14), 166.13 (C-11), 159.89 (C-6), 153.59 (C-4), 138.56 (C-1), 131.74 (C4a), 128.58 (C-8), 124.04 (C-7), 123.67 (C-8a), 120.78 (C-3), 103.36 (C-5), 70.65 (C-9), 40.94 (C-13), 21.69 (C-10/10'), 21.59 (C-10/10').

Compound $3,{ }^{1} \mathrm{H}$ NMR (DMSO- $\left.d_{6}\right), \delta: 13.54(\mathrm{~s}, 1 \mathrm{H}, \mathrm{OH}-4)$, $12.81(\mathrm{~s}$, broad, $1 \mathrm{H}), 9.27(\mathrm{t}, \mathrm{J}=6.2 \mathrm{~Hz}, 1 \mathrm{H}, \mathrm{NH}-12), 8.78$ (s, 1H, CH-1), $8.20(\mathrm{~d}, \mathrm{~J}=9.1 \mathrm{~Hz}, 1 \mathrm{H}, \mathrm{CH}-5), 7.65(\mathrm{~d}, \mathrm{~J}=$ $2.3 \mathrm{~Hz}, 1 \mathrm{H}, \mathrm{CH}-8), 7.47$ (dd, J = 9.1/2.3 Hz, 1H, CH-6), 4.90 (sept, J = 6.0, 1H, CH-9), $4.06(\mathrm{~d}, \mathrm{~J}=6.2 \mathrm{~Hz}, 2 \mathrm{H}$, $\left.\mathrm{CH}_{2}-13\right), 1.44\left(\mathrm{~d}, \mathrm{~J}=6.0 \mathrm{~Hz}, 6 \mathrm{H}, \mathrm{CH}_{3}-10 / 10^{\prime}\right) ;{ }^{13} \mathrm{C} \mathrm{NMR}$ (DMSO- $\left.d_{6}\right), \delta: 170.91$ (C-14), 170.31 (C-11), 158.73 (C-7), 154.43 (C-4), 141.30 (C-1), 133.47 (C-8a), 124.10 (C-5), 123.38 (C-6), 121.70 (C-4a), 120.51 (C-3), 108.04 (C-8), 70.14 (C-9), 40.79 (C-13), 21.82 (C-10/10').

Compound 4, ${ }^{1} \mathrm{H}$ NMR $\left(\mathrm{CDCl}_{3}\right), \delta: 12.98(\mathrm{~s}, 1 \mathrm{H}), 8.17$ (broad m, 1H, NH-12), $8.10(\mathrm{~d}, \mathrm{~J}=9.1 \mathrm{~Hz}, 1 \mathrm{H}, \mathrm{CH}-8)$, $7.56(\mathrm{~d}, \mathrm{~J}=2.5 \mathrm{~Hz}, 1 \mathrm{H}, \mathrm{CH}-5), 7.31(\mathrm{dd}, \mathrm{J}=9.1 / 2.5 \mathrm{~Hz}$, 1H, CH-7), 4.81 (sept, J = 6.0 Hz, 1H, CH-9), 3.90 (t, J = 
$\left.5.2 \mathrm{~Hz}, 2 \mathrm{H}, \mathrm{CH}_{2}-14\right), 3.68$ (m, 2H, $\left.\mathrm{CH}_{2}-13\right), 1.44$ (d, J = $\left.6.0 \mathrm{~Hz}, 6 \mathrm{H}, \mathrm{CH}_{3}-10 / 10^{\prime}\right) ;{ }^{13} \mathrm{C} \mathrm{NMR}\left(\mathrm{CDCl}_{3}\right), \delta: 169.84$ (C-11), 159.95 (C-6), 153.85 (C-4), 139.21 (C-1), 132.20 (C-4a), 128.36 (C-8), 123.96 (C-7), 123.76 (C-8a), 120.64 (C-3), 103.09 (C-5), 70.64 (C-9), 62.18 (C-14), 42.10 (C-13), $231.70\left(\mathrm{C}-10 / 10^{\prime}\right)$.

Compound $5,{ }^{1} \mathrm{H}$ NMR (acetone- $\left.d_{6}\right), \delta: 8.34(\mathrm{~d}, \mathrm{~J}=9.0$ $\mathrm{Hz}, 1 \mathrm{H}, \mathrm{H}-5), 7.60$ (d, J = $2.5 \mathrm{~Hz}, 1 \mathrm{H}, \mathrm{H}-8), 7.59$ (dd, J = 9.0/2.5 Hz, 1H, H-6), 4.99 (sept, J = 6.0 Hz, 1H, H-9), $1.45\left(\mathrm{~d}, \mathrm{~J}=6.0 \mathrm{~Hz}, 6 \mathrm{H}, \mathrm{H}-10 / 10^{\prime}\right) ;{ }^{13} \mathrm{C}$ NMR (acetone$\left.d_{6}\right), \delta: 171.25$ (C-13), 161.23 (C-7), 156.57 (C-4), 138.37 (C-1), 132.35 (C-8a/C-4a), 125.95 (C- 5), 124.14 (C-6), 123.86 (C-8a/C-4a), 117.86 (C-3), 107.36 (C-8), 71.16 (C-9), 21.38 (C-10/10').

Compound 6, ${ }^{1} \mathrm{H}$ NMR (acetone- $\left.d_{6}\right), \delta: 8.30(\mathrm{~d}, \mathrm{~J}=9.0$ $\mathrm{Hz}, 1 \mathrm{H}, \mathrm{CH}-5), 7.58$ (d, J = 2.4 Hz, 1H, CH-8), 7.54 (dd, $\mathrm{J}=9.0 / 2.4 \mathrm{~Hz}, 1 \mathrm{H}, \mathrm{CH}-6), 4.96$ (sept, J = 6.1, 1H, CH-9), $1.44\left(\mathrm{~d}, \mathrm{~J}=6.1 \mathrm{~Hz}, 6 \mathrm{H}, \mathrm{CH}_{3}-10 / 10^{\prime}\right) ;{ }^{13} \mathrm{C}$ NMR (acetone$\left.d_{6}\right), \delta: 170.34$ (C-14), 169.51 (C-11), 160.58 (C-7), 154.95 (C-4), 137.75 (C-1), 131.63 (C-8a), 125.51 (C-5), 124.68 (C-6), 124.02 (C-4a), 119.71 (C-3), 107.36 (C-8), 70.91 (C-9), 29.42 (m, C-13), 21.44 (C-10/10').

\section{Electrospray Ionization-Tandem Mass Spectrometry}

Compound 1. To identify the protonation site, which is important for the discussion of the dissociation pathway, density functional theory calculations of proton affinities at isoquinoline nitrogen (Figure 1, N-2) and amide oxygen (CO-11) were conducted. Assuming a conformationally rigid glycine amide residue that allows for several stabilizing hydrogen bonds to be formed, almost isoenergetic affinities at both positions indicate that protonation can principally occur at both sites (data not shown). However, in an excited-state, the $\mathrm{CO}_{2}$-function is unlikely to be fixed in one conformation as rotation around the bonds $\mathrm{C} 13-\mathrm{C} 14$ and N12-C13 can occur. In the case of a conformationally flexible side-chain, protonation at N-2 was found to be energetically favored.

Collisional activation of N-protonated N-[(1-Chloro-4hydroxy-7-isopropoxy-isoquinolin-3-yl)carbonyl]glycine results in consecutive losses of water $(-18 \mathrm{u})$ and carbon monoxide $(-28 \mathrm{u})$ giving rise to the product ions at $\mathrm{m} / \mathrm{z}$ 321 and 293, respectively (Figure 2a, Table 1, Compound 1). Besides the losses of water and carbon monoxide, the precursor ion $[\mathrm{M}+\mathrm{H}]^{+}$generates a fragment ion at $m / z 238$ by the elimination of $\mathrm{C}_{3} \mathrm{H}_{3} \mathrm{NO}_{3}$ $(-101 \mathrm{u})$. As verified by means of $\mathrm{MS}^{3}$ and $\mathrm{MS}^{4}$ experiments, the abundant ion at $m / z 282$ was shown to originate from the precursor at $m / z 293$, corresponding to a mass shift of $-11 \mathrm{u}$, and, according to the elemental composition of the product ions, to a nominal loss of $\mathrm{HCN}$, concerted with the addition of an oxygen atom. Simultaneously, the fragment ion at $m / z 293$ eliminates $\mathrm{CH}_{2} \mathrm{NH}(-29 \mathrm{u})$ to yield the product ion at $m / z 264$, which, upon isolation and storage in the linear ion trap, spontaneously adds a water molecule $(+18 \mathrm{u})$ to create the same product ion at $m / z$ 282. Ultimately, $\mathrm{MS}^{3}$ experiments with $m / z 293$ as precursor ion generate a product ion at $m / z 251$ by elimination of $\mathrm{C}_{3} \mathrm{H}_{6}(-42 \mathrm{u})$. This ion, only observed under $\mathrm{MS}^{n}(n>2)$ conditions, shows a similar dissociation pattern as its precursor at $m / z 293$ with nominal losses of $11 \mathrm{u}$ and $29 \mathrm{u}$ yielding the product ions at $\mathrm{m} / \mathrm{z} 240$ and 222, respectively (MS ${ }^{4}$, Table 1). Again, the same product ions are obtained by excitation of the ion at $m / z 264$ through elimination of $\mathrm{C}_{3} \mathrm{H}_{6}(-42 \mathrm{u}, m / z 222)$ and subsequent addition of water $(+18 \mathrm{u}, \mathrm{m} / \mathrm{z} 240)$. $\mathrm{MS}^{4}$ experiments proved that the product ion at $m / z 222$ gives rise to the fragment ions at $\mathrm{m} / \mathrm{z} 194$ and 166 by consecutive losses of two molecules of carbon monoxide $(-28 \mathrm{u},-28 \mathrm{u})$, as well as to the ion at $m / z 212$, corresponding to a nominal loss of $10 u$ (-"C" $/+$ " $\left.2 \mathrm{H}^{\prime \prime}\right)$. Similar to the ions at $m / z 264$ and 222, the product ion at $m / z 194$, upon storage in the ion trap, adds a water molecule $(+18 \mathrm{u})$ to yield the ion at $m / z$ 212 with the same elemental composition as the one mentioned above (Table 1).

This unusual dissociation pathway is in accordance with the previously reported mass spectrometric behavior of structurally related isoquinoline-3-carboxamides also including a nominal loss of $11 \mathrm{u}$ [10]. This was attributed to the elimination of $\mathrm{HCN}(-27 \mathrm{u})$ forming a reactive carbene intermediate which was suggested to rapidly add an oxygen atom $(+16 \mathrm{u})$. Due to the mass spectrometric data on isoquinoline-3-carboxamide 1 revealing a more complex fragmentation pathway as well as another observed unusual nominal loss of $10 \mathrm{u}$, additional experiments were conducted to elucidate the dissociation mechanism causing these atypical findings.

As described above, the ion at $m / z 282$ is formally generated from $\mathrm{m} / \mathrm{z} 293$ by elimination of HCN concerted with the addition of oxygen. Alternatively, this ion can be formed by elimination of methyleneamine $(-29 \mathrm{u})$ from the $m / z 293$ precursor to form a putative acylium ion intermediate at $\mathrm{m} / \mathrm{z} 264$ which subsequently associates a water molecule $(+18 \mathrm{u})$ to yield the ion at $m / z$ 282. DFT calculation of the reaction energies of the two different dissociation pathways revealed the acylium ion route including water adduct formation in the gas-phase to be thermodynamically privileged by 16 $\mathrm{kcal} / \mathrm{mol}$ as compared to the previously supposed route via a reactive carbene intermediate.

To unequivocally identify the definite dissociation pathway, an isotope labeled analogue of $\mathbf{1}$ bearing two deuterium atoms at C-13 was synthesized and analyzed (Compound 6, Figure 1 and 2b, Table 1). The doubly deuterated and protonated precursor at $m / z 341$ consecutively eliminates water $(-18 \mathrm{u})$ and carbon monoxide $(-28 \mathrm{u})$ to yield the product ion at $m / z 295$ still including both deuterium atoms. In case of the suggested carbene pathway, DCN elimination $(-28 \mathrm{u})$ and subsequent oxygen addition $(+16 \mathrm{u})$ in the $\mathrm{MS}^{3}$ spectrum of the ion at $m / z 295$ should reveal the formation of a singly deuterated product ion at $\mathrm{m} / \mathrm{z} 283(-12 \mathrm{u})$. Instead, both deuterium labels are eliminated from the 
<smiles>CC(C)Oc1ccc2c(O)c(C(=O)NCC(=O)O)nc(Cl)c2c1</smiles>

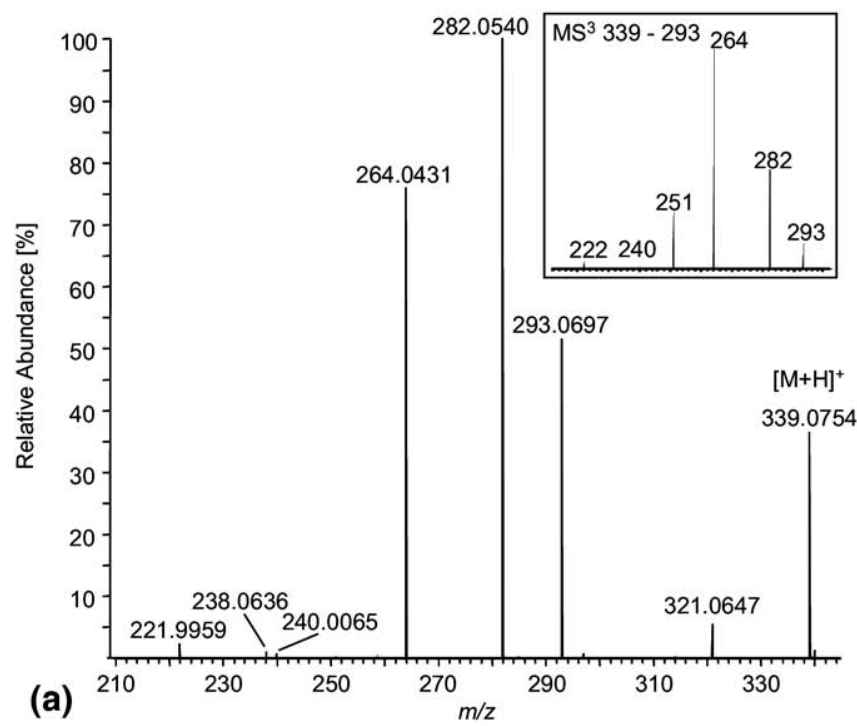<smiles>[2H]C([2H])(NC(=O)c1nc(Cl)c2cc(OC(C)C)ccc2c1O)C(=O)O</smiles>

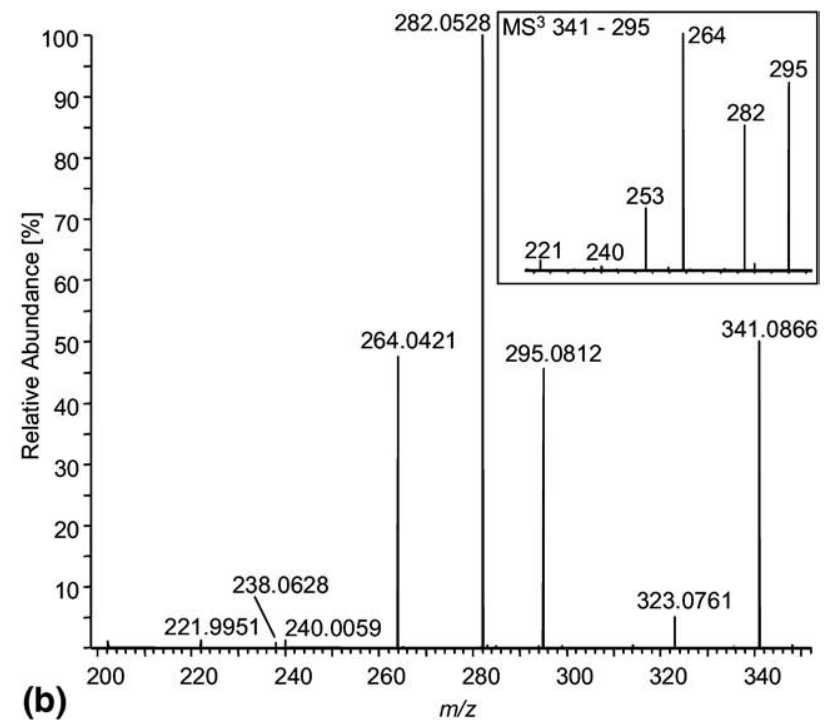

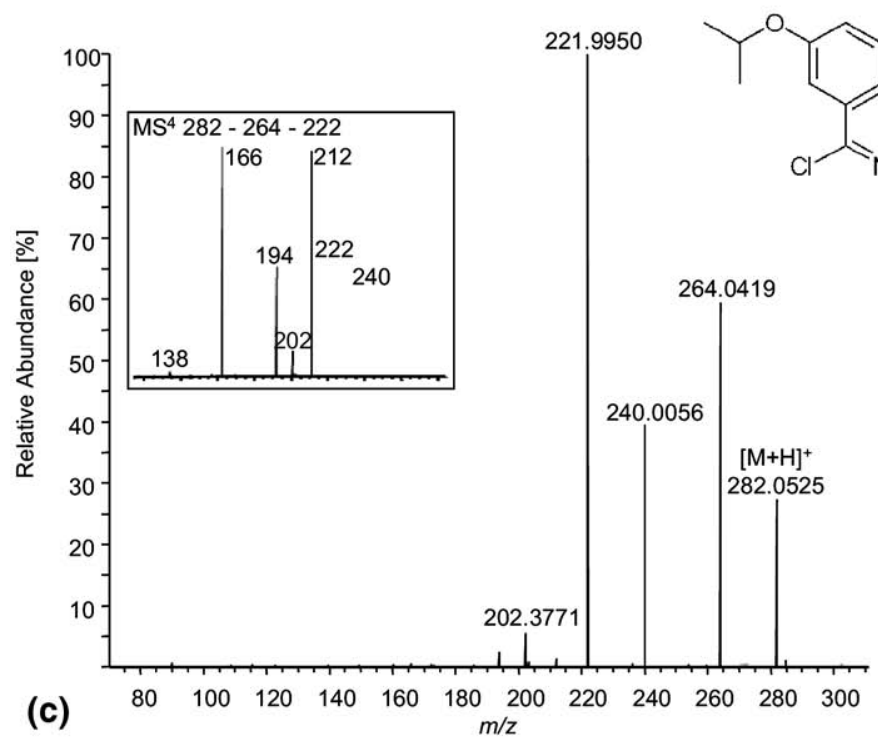

Figure 2. ESI product ion spectra (LTQ-Orbitrap) of protonated (a) Compound 1, collision energy $(\mathrm{CE})=25$ arbitrary units (au), $\mathrm{MS}^{3}$ experiment $\mathrm{CE}=19 \mathrm{au}$; (b) Compound 6, collision energy $=25$ arbitrary units, $\mathrm{MS}^{3}$ experiment $\mathrm{CE}=18 \mathrm{au}$; (c) Compound 5, collision energy $=25$ arbitrary units, $\mathrm{MS}^{4}$ experiment $\mathrm{CE}=15$ au.

precursor at $m / z 295$ and the same product ions as in the spectrum of the unlabelled Compound 1 are observed $(\mathrm{m} / \mathrm{z} 282,264,240$, and 222, Table 1, Compound 6). Isolation of the ion at $m / z 264$, generated by $\mathrm{MS}^{2}$ or $\mathrm{MS}^{3}$ fragmentation of the precursors at $\mathrm{m} / \mathrm{z} 341$ or 295 , respectively, also yields the same water adduct at $\mathrm{m} / \mathrm{z}$ 282 as Compound 1 (Table 1, 6). Together, these findings clearly exclude the dissociation mechanism via the reactive carbene intermediate in favor of the methyleneamine elimination pathway via the acylium ion at $\mathrm{m} / \mathrm{z}$
264, which subsequently associates a water molecule to yield the ion at $m / z 282$.

Moreover, the intermediate fragment ion of the deuterated precursor at $m / z 295$ generates a product ion at $m / z 253\left(-42 \mathrm{u}\right.$, Table 1, Compound 6) which, upon $\mathrm{MS}^{4}$ excitation, yields the ions at $\mathrm{m} / \mathrm{z} 240$ and $222(-13 \mathrm{u}$, $-31 \mathrm{u}$, respectively). These ions undergo the same water addition pattern as observed for $\mathrm{m} / \mathrm{z} 264$ and 282 . Finally, the protonated molecule of Compound 6 at $\mathrm{m} / \mathrm{z}$ 341 eliminates $\mathrm{C}_{3} \mathrm{HD}_{2} \mathrm{NO}_{3}(-103 \mathrm{u})$ to produce the ion 


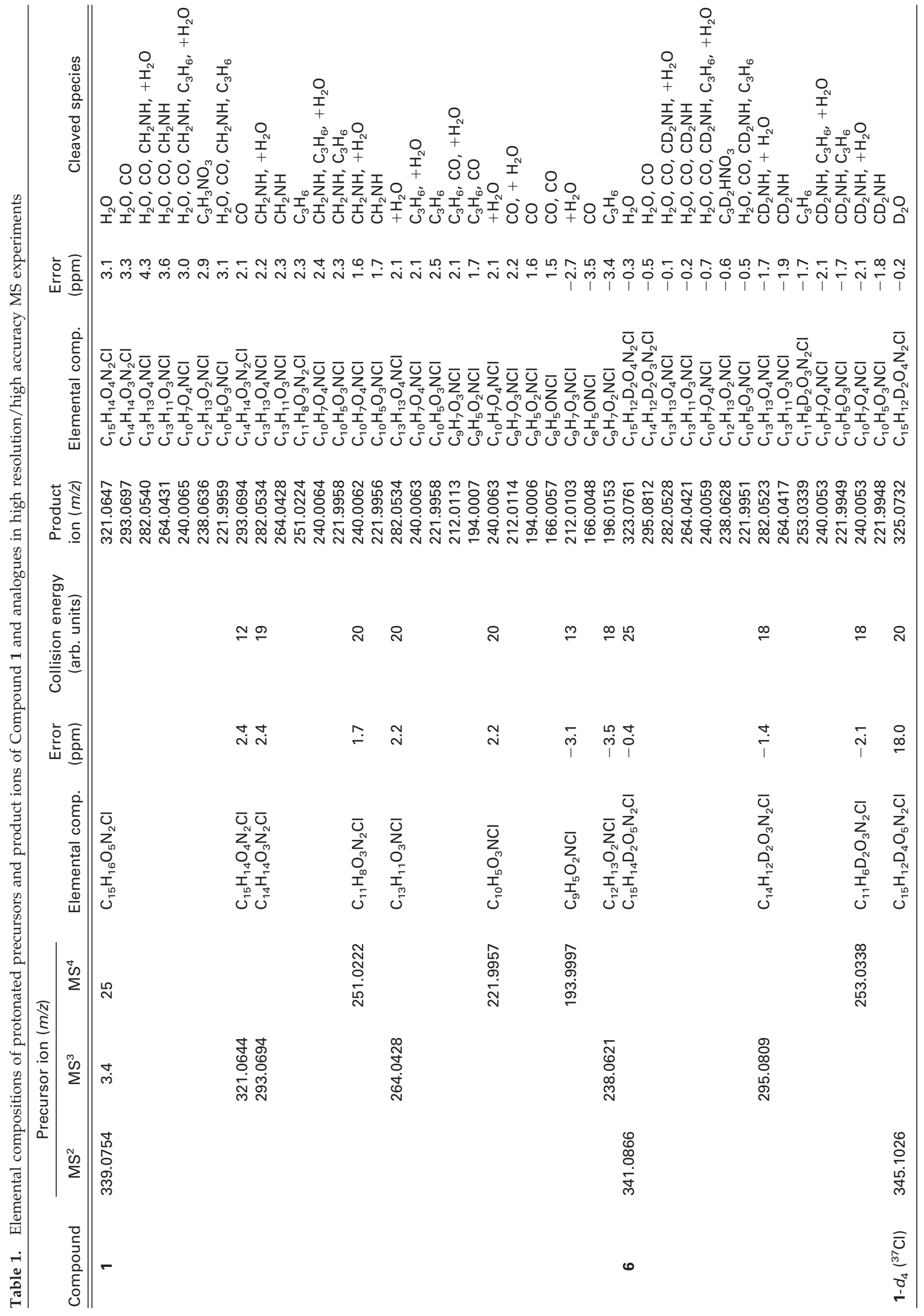




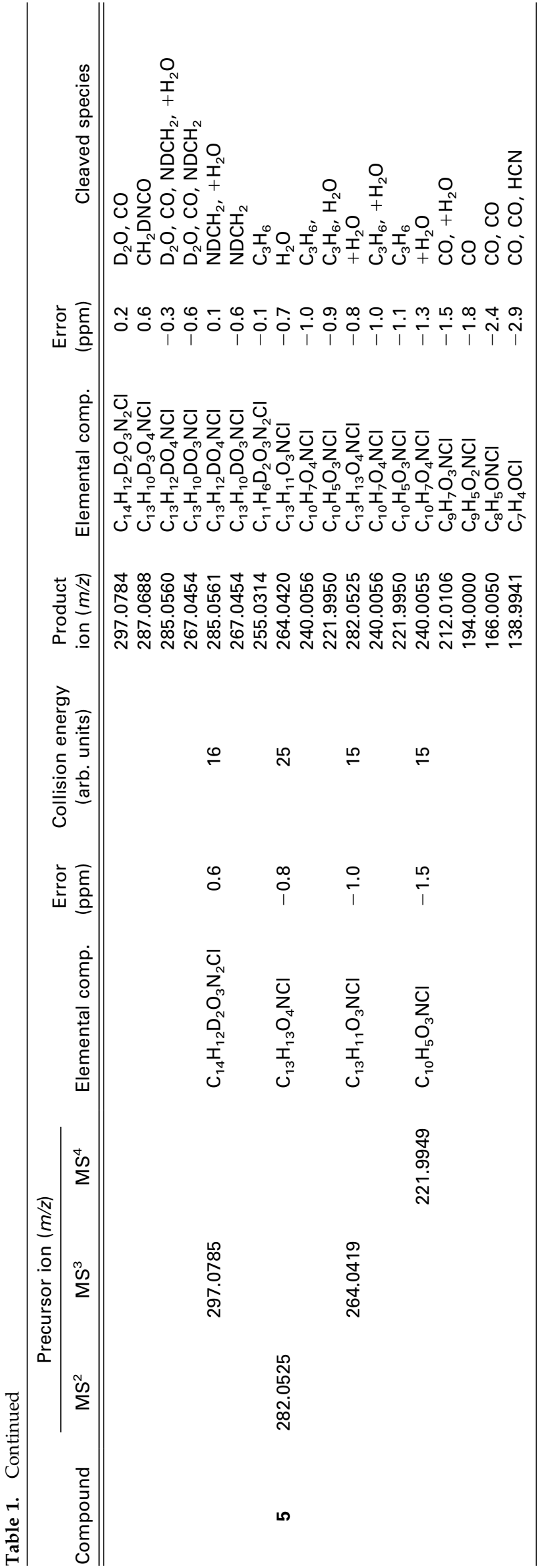

at $\mathrm{m} / \mathrm{z} 238$ while all dissociations in the lower mass region of the spectrum generate the same product ions as in the case of the unlabelled Compound $\mathbf{1}$.

Exchange of mobile protons by deuterons and subsequent ionization from $\mathrm{D}_{2} \mathrm{O} /$ methanol- $d$ yields the $d_{4}$-analogue of Compound $1(\mathrm{~m} / \mathrm{z} 343)$. To exclude interferences with the ${ }^{37} \mathrm{Cl}$ isotope of the molecule obtained from two H/D exchanges (also $\mathrm{m} / \mathrm{z} 343$ ), the ${ }^{37} \mathrm{Cl} d_{4}$-isotope at $\mathrm{m} / \mathrm{z} 345$ was subjected to MS/MS experiments (Table 1, Compound $1-d_{4}\left[{ }^{37} \mathrm{Cl}\right]$ ). Evidence was furnished for the loss of $\mathrm{D}_{2} \mathrm{O}(-20 \mathrm{u})$ yielding the product ion at $\mathrm{m} / \mathrm{z} 325$ which subsequently eliminates $\mathrm{CO}(-28 \mathrm{u})$ to generate the doubly deuteronated product ion at $\mathrm{m} / \mathrm{z} 297$. In accordance with the mechanism presumed above, this ion gives rise to the product ions at $\mathrm{m} / \mathrm{z} 267$ (-CHDNH, $30 \mathrm{u}), 285(-\mathrm{CHDNH}, 30 \mathrm{u}$; + $\left.\mathrm{H}_{2} \mathrm{O}, 18 \mathrm{u}\right)$, and $255\left(-\mathrm{C}_{3} \mathrm{H}_{6}, 42 \mathrm{u}\right)$ in $\mathrm{MS}^{3}$ experiments (Table 1).

Based on these data, dissociation pathways for the protonated molecule $\mathbf{1}$ and a general mechanism for the nominal losses of 10 and $11 \mathrm{u}$ in the mass spectra of isoquinoline-3-carboxamides are proposed. As shown in Scheme 2, the protonated precursor of $\mathbf{1}(\mathrm{m} / \mathrm{z} 339)$ eliminates water and carbon monoxide to yield the 1-chloro4-hydroxy-7-isopropoxy-isoquinoline-3-carboxylic acid methyleneamide cation (pathway $a$ ). Hydrogen transfer from the protonation site to the nitrogen atom of the leaving group and subsequent elimination of methyleneamine $(b)$ generates the isoquinoline-3-acylium ion at $m / z$ 264, which reversibly (vide infra) adds a water molecule to produce the isoquinoline-3-carboxylic acid cation $(c, m / z 282)$. Hence, the nominal loss of $11 \mathrm{u}$ is suggested to be actually composed of a methyleneamine elimination $(-27 \mathrm{u})$ and an instantaneous water addition $(+18 \mathrm{u})$ via an acylium ion intermediate.

As reported earlier, the water association in the gas phase of the mass spectrometer appeared to be highly reversible, allowing for $\mathrm{MS}^{n}$ "ping-pong" experiments (up to $\mathrm{MS}^{7}$ to be conducted in the linear ion trap, where storage of the isoquinoline-3-acylium ion spontaneously produces the carboxylic acid as water adduct, which, upon excitation, re-eliminates the water molecule to restore the initial anhydride ion structure (data not shown). The inability to fully decompose the ion at $\mathrm{m} / \mathrm{z} 282$ even by application of high excitation energies (up to $100 \mathrm{eV}$ ) further substantiates the high spontaneousness of the acylium ion-water association explaining the favored gas-phase ion structure of the isoquinoline3-carboxylic acid.

The same reversible gas-phase water addition pathway is observed between the 1-chloro-4,7-dihydroxyisoquinoline-3-acylium ion $(\mathrm{m} / \mathrm{z} 222)$ and the corresponding carboxylic acid $(\mathrm{m} / \mathrm{z} 240$, e) after propene elimination (Scheme 2, pathway d). This set of fragment ions can also be generated via an alternative route $f$, e.g., by initial propene elimination to yield the 1-chloro-4,7dihydroxy-isoquinoline-3-carboxylic acid methyleneamide cation at $\mathrm{m} / \mathrm{z} 251$ and subsequent loss of methyleneamine. Further evidence for the reversible gas-phase water 
addition pattern is furnished by another unusual nominal loss of $10 \mathrm{u}$ that can be explained by this phenomenon: The acylium function of the product ion at $m / z 222$ is eliminated as carbon monoxide to yield the charge-delocalized 1-chloro-4,7-dihydroxyisoquinoline-carbenium ion $(h)$, which, again reversibly, re-associates water to yield a trihydroxyisoquinoline cation, such as the protonated 1-chloro-3,4,7-dihydroxyisoquinoline (i).

In another fragmentation route, the precursor at $m / z$ 339 yields a product ion at $m / z 238$, which is proposed to be generated by nucleophilic attack of the carboxylic oxygen at the amide carbon, concomitant hydrogen transfer, and final elimination of $\mathrm{C}_{3} \mathrm{H}_{3} \mathrm{NO}_{3}$, such as thermodynamically stable 2,5-oxazolidinedione (route $k$ ).

The proposed gas-phase structures shown in Scheme 3 agree with the previously reported dissociation of related isoquinoline-3-carboxamides [10]. They could additionally be substantiated by the analysis of chemically synthesized 1-chloro-4-hydroxy-7-isopropoxyisoquinoline-3-carboxylic acid (Compound 5, Figure 1, Scheme 1) constituting the proposed gas-phase structure of the water adduct ion at $m / z 282$ which generates the same product ions in offline ESI-MS ${ }^{n}$ experiments as the protonated molecule of Compound 1 (Figure 2c, Table 1, 5).

Compounds 2-4. The CID behavior of protonated molecules of 2-4 basically follow the same pattern as described in detail for Compound $\mathbf{1}$ above (Figure 3, Table 2). In accordance to 1 , the product ion spectrum of the protonated 6-isopropoxy analogue (Figure 1, Compound 2) reveals the same set of fragment ions and characteristic ion transitions (nominal losses of 11 and $10 \mathrm{u}$, multiple reversible water addition to fragment ions) with two additional signals at $\mathrm{m} / \mathrm{z} 297$ and 251
(Figure 3a, Table 2, 2) originating from the immediate cleavage of the 6-isopropoxy function from the precursor at $m / z 339(-42 \mathbf{u} ; m / z 297)$ and subsequent losses of water and carbon monoxide (-18 u, $-28 \mathrm{u} ; m / z 251)$, respectively. Assuming a protonation at N-2, the favored propene elimination from the precursor at $\mathrm{m} / \mathrm{z}$ 339 could be due to a possible delocalization of the positive charge to the 6-isopropoxy oxygen, thus potentially facilitating the dissociation of the isopropoxy-C-O bond (Scheme 3a). For Compound 1, which is lacking evidence for initial propene elimination, the corresponding resonance structure cannot be formulated. In fact, DFT calculations of the partial charge at isopropoxy-oxygen (natural bond order charge analysis) for the N-protonated Compounds $\mathbf{1}$ and $\mathbf{2}$ proved the oxygen in 2 to be less negatively charged $(-0.390$ for 2 ; -0.398 for 1), indicating a higher contribution of resonance structure 339b (Scheme 3a) to the actual electron distribution of protonated 2.

Moreover, $\mathrm{MS}^{3}$ experiments with the acylium ion at $\mathrm{m} / \mathrm{z} 264$ yield two additional fragment ions at $\mathrm{m} / \mathrm{z} 254$ $(-10 \mathrm{u})$ and $236(-28 \mathrm{u}$; Table 2, Compound 2), corresponding to an elimination of carbon monoxide $(\mathrm{m} / \mathrm{z}$ 236), concerted with the association of a water molecule $(\mathrm{m} / \mathrm{z} 254$, Table 2$)$. Interestingly, the nominal loss of $10 \mathrm{u}$ at this stage of the dissociation pathway is favored because the propene elimination, which is readily observed in case of Compound $\mathbf{1}$ yielding the product ion at $m / z 222$, seems to be impeded for the 6-isopropoxy isomer. In contrast to the precursor at $m / z 339$, initial localization of the positive charge at the 3-acylium ion function of the isoquinoline ring allows for the formulation of a resonance structure with positively charged isopropoxy-oxygen only if it is linked to the 7-position of the heterocycle. This is believed to explain the preferred propene elimination from the 7-isopropoxy-

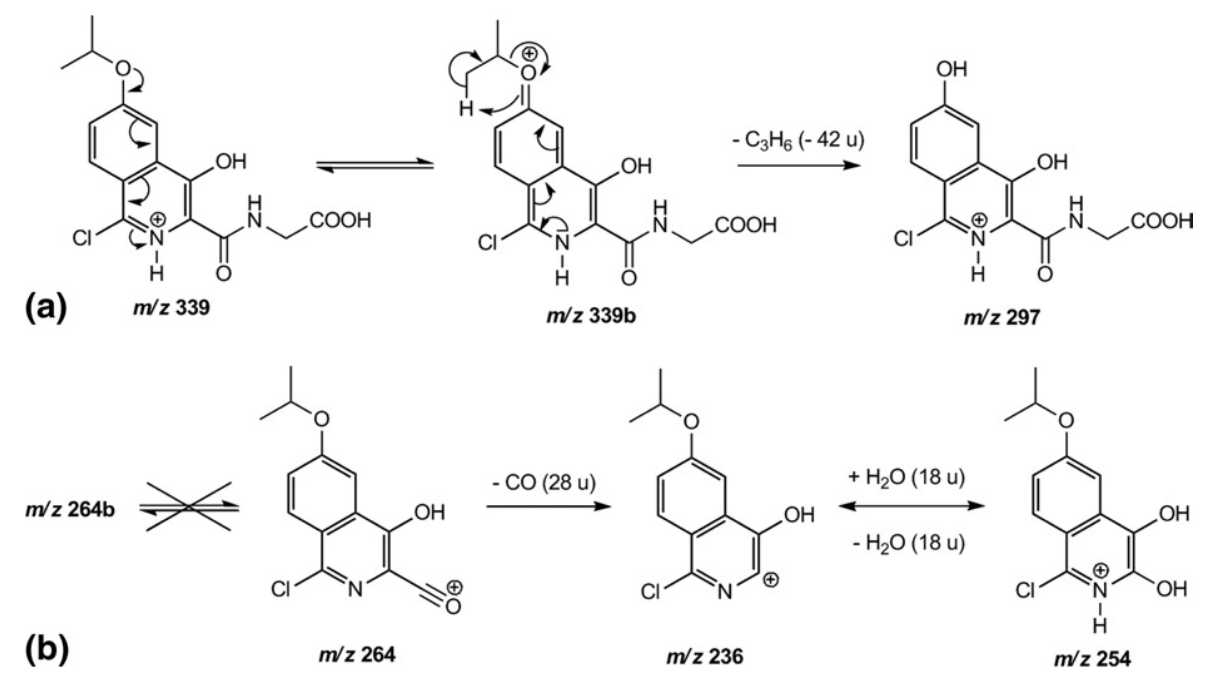

Scheme 3. (a) Possible charge delocalization in protonated Compound 2, facilitating the elimination of propene from resonance structure $\mathrm{m} / \mathrm{z} 339 \mathrm{~b}$. (b) Accordant delocalization is not possible in product ion at $\mathrm{m} / \mathrm{z} 264$, therefore the immediate propene elimination is hindered and CO elimination is favored. For the analogous product ion at $\mathrm{m} / \mathrm{z} 264$ of Compound 1, which only eliminates propene, a resonance structure $264 \mathrm{~b}$ can be formulated (not shown). 

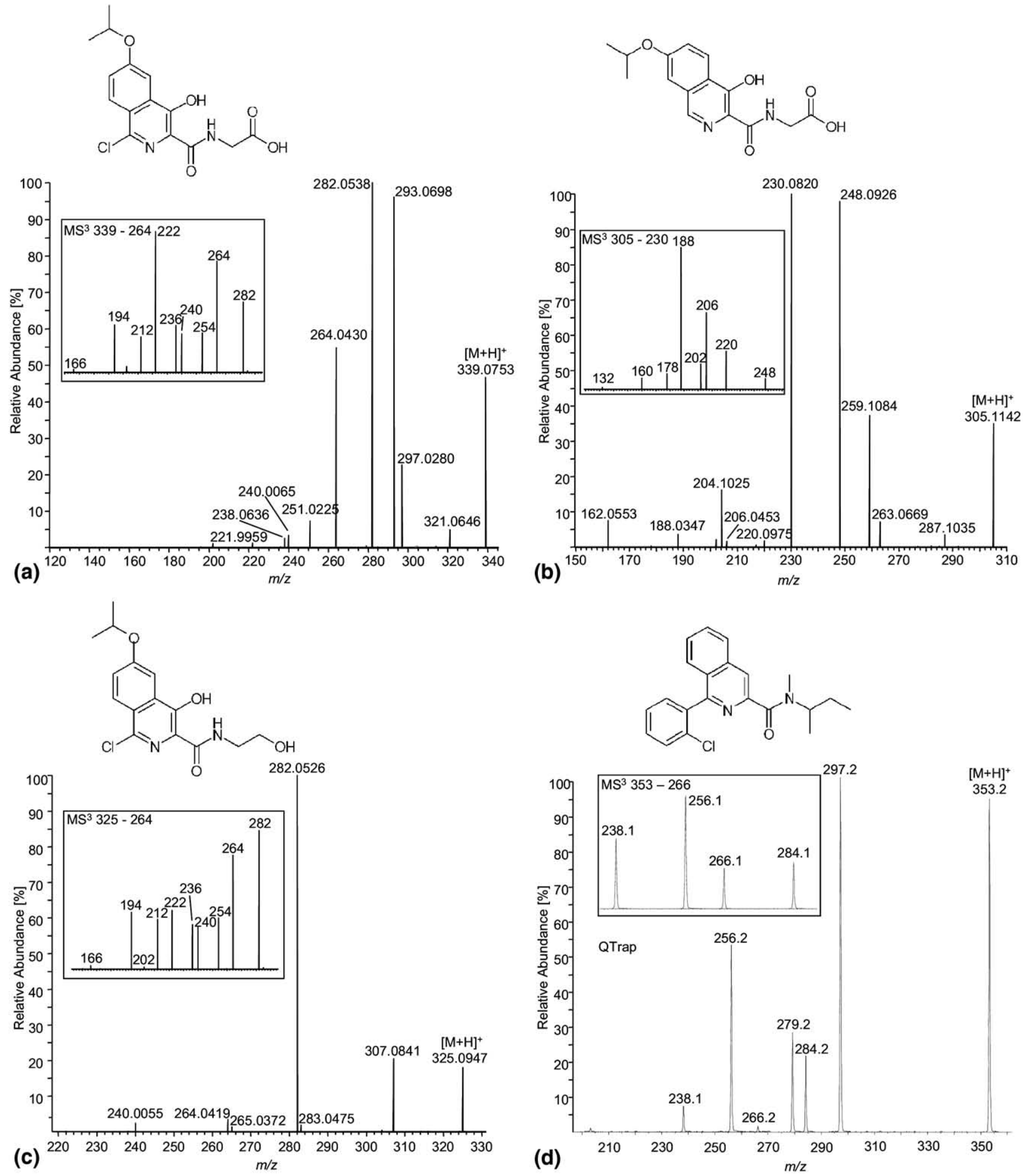

Figure 3. ESI product ion spectra (LTQ-Orbitrap) of protonated (a) Compound 2, collision energy $(\mathrm{CE})=25$ arbitrary units (au), $\mathrm{MS}^{3}$ experiment $\mathrm{CE}=18$ au; (b) Compound 3, collision energy $=25$ arbitrary units, $\mathrm{MS}^{3}$ experiment $\mathrm{CE}=30 \mathrm{au}$; (c) Compound 4, collision energy $=23$ arbitrary units, $\mathrm{MS}^{3} \mathrm{CE}=15 \mathrm{au}$; (d) ESI product ion spectrum (QTrap) of Compound 7, collision energy $=25$ arbitrary units, $\mathrm{MS}^{3}$ experiment excitation energy $=18 \mathrm{au}$.

isoquinoline-3-acylium ion (originating from 1) while the 6-isopropoxy isomer 2 additionally generates the isoquinoline carbenium ion at $\mathrm{m} / \mathrm{z} 236$ and the cation at $\mathrm{m} / \mathrm{z} 254$, such as the protonated 1-chloro-6-isopropoxy- 3,4-dihydroxy isoquinoline, by subsequent water adduct formation (Scheme 3b).

Protonated Compound 3 ( $m / z$ 305, Figure 1) dissociates via the same routes as described above for Com- 


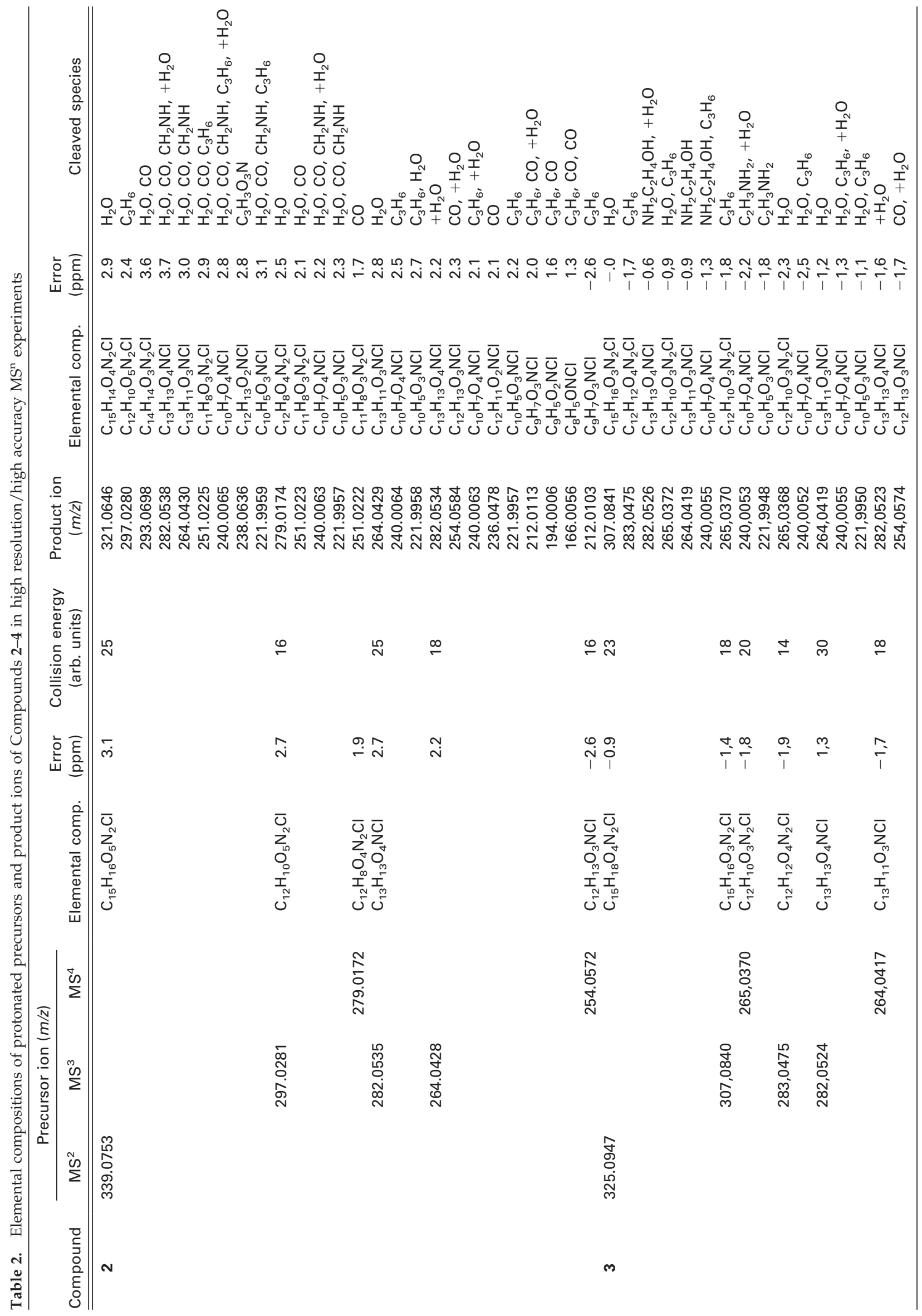




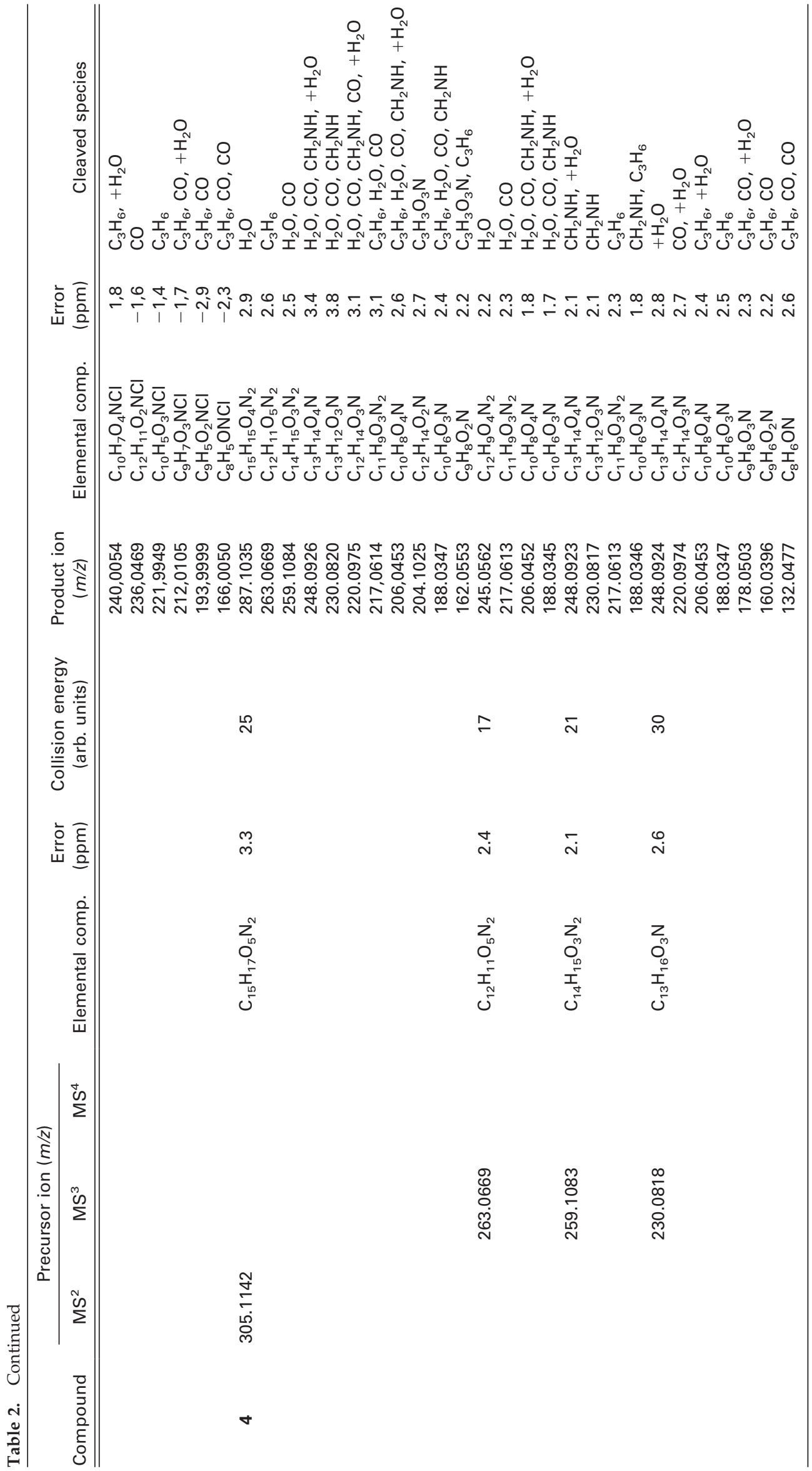


pounds 1 and 2 (Figure 3b, Table 2). However, as the loss of $42 \mathrm{u}\left(-\mathrm{C}_{3} \mathrm{H}_{6}\right)$ is observed in all stages of the fragmentation, the increase of electron density in the aromatic isoquinoline ring system by chemical removal of the electronegative chlorine atom seems to compensate for the direction of propene elimination (vide supra). Another effect of the change in electron distribution might be the favored elimination of 2,5-oxazolidinedione $(-101 \mathrm{u})$ from the precursor at $\mathrm{m} / \mathrm{z} 305$ to form the abundant ion at $\mathrm{m} / \mathrm{z} 204$ (Figure $3 b)$, supposedly the protonated 4-hydroxy-7isopropoxy-isoquinoline.

CID of protonated Compound 4 ( $\mathrm{m} / \mathrm{z}$ 325, Figure 1) finally substantiates the general validity of the postulated fragmentation behavior of substituted 4-hydroxyisoquinoline-3-carboxamides: The same characteristic reversible water addition pattern giving rise to the favored gas-phase ion structure of protonated isoquinoline-3carboxylic acids is observed (Figure 3c, Table 2) even though the initial fragmentation route is modified by substitution of a 2-ethanolamide residue for the $\mathrm{N}$ glycinamide function (Scheme 1). Besides the ion at $\mathrm{m} / \mathrm{z}$ 307 , originating from initial water elimination, the most abundant ion at $m / z 282$ is generated by immediate loss of ethanolamine from the precursor at $\mathrm{m} / \mathrm{z} 325$ to form the isoquinoline-3-acylium ion at $m / z 264$ and subsequent spontaneous water addition. All fragment ions resulting from $\mathrm{m} / \mathrm{z} 264$ coincide with the product ions of protonated 2 (Table 2), ultimately corroborating the postulated dissociation pathways and mechanisms.

The minimum prerequisite for the observed distinctive fragmentation behavior of substituted isoquinolines seems to be the isoquinoline-3-carboxamide core, whereas the effects of substituents on the heterocycle and the kind of amide bond residue, e.g., amino acetic acid, ethanolamine, amine, etc., are negligible. Evidence for this is furnished by the mass spectrum of protonated PK11195 [1-(chlorophenyl)-N-methyl-N-(-1-methylpropyl)-3isoquinoline carboxamide] (Figure 1, Compound 7), a widely used clinical tracer $\left({ }^{11} \mathrm{C}-\mathrm{PK} 11195\right)$ for the visualization of neuronal damage by positron emission spectroscopy [29], which also comprises an isoquinoline3-carboxamide core and undergoes a similar characteristic fragmentation, despite different substitution pattern. To prove the phenomena to be independent from the instrumental layout of the mass spectrometer, an API 2000 QTrap instrument was used for this experiment. CID of the protonated precursor at $\mathrm{m} / \mathrm{z} 353$ gives rise to a mass spectrum (Figure $3 \mathrm{~d}$ ) including two reversible water addition steps $(\mathrm{m} / \mathrm{z} 266-284 ; \mathrm{m} / \mathrm{z} 238$ $-256)$ and nominal losses of $13 \mathrm{u}$ from the precursor ion at $m / z 297$ and $10 \mathrm{u}$ from $m / z$ 266, respectively, in $\mathrm{MS}^{3}$ experiments. In fact, analysis of all presented compounds on the API 2000 QTrap mass spectrometer in positive ESI mode yielded the same product ions as obtained with the LTQ-Orbitrap (data not shown), even if in-space instead of in-time dissociation is applied.

Stunningly, the source of the gas-phase water responsible for the unusual observations remains unclear.
The water molecule initially (and irreversibly) cleaved from the precursor ions at 339 (1, 2), 305 (3), and 325 (4), respectively, as well as the solvation/ionization process could be ruled out as origin of the water addition by $\mathrm{H} / \mathrm{D}$-exchange experiments (vide supra) and the use of deuterium oxide as infusion solvent. Attempts to exchange potential residual water in the Orbitrap as well as the QTrap mass spectrometer by direct infusion of deuterium oxide/methanol- $d$ at an average flow rate of $5 \mu \mathrm{L} / \mathrm{min}$ for $72 \mathrm{~h}$ did not affect the masses of the relevant fragment ions. Moreover, the nitrogen generator could be excluded as moisture source by application of commercial dry nitrogen (purity grade 5.0) as sheath and collision gas to the QTrap mass spectrometer. The identification of the source of neutral reactants within mass spectrometers was shown to be a highly complex task also in earlier studies, which reported on similar solvation phenomena with different acylium fragment ions in quadrupole ion trap and Fourier transform ion cyclotron resonance mass spectrometers [20]. In accordance with that, the origin as well as the driving force for the described phenomena yet remains to be clarified.

\section{Conclusion}

Mass spectrometric investigation of protonated isoquinoline-3-carboxamides, a class of drug candidates that are of urgent interest in preventive doping research, yielded atypical dissociation pathways, including multiple, reversible water association of acylium fragment ions at several stages. This allowed for the formulation of fragmentation mechanisms characteristic for this compound class. Aiming at analytical assay development with QTrap mass spectrometers, neutral loss scans for $11 \mathrm{u}$ could be utilized in screenings for substituted (isoquinoline-3-carboxy)glycines, whereas a neutral loss of $10 \mathrm{u}$ is shown to serve as potential diagnostic ion transition for compounds comprising an isoquinoline-3-carboxamide core. This enables the detection of potential metabolites and a wide variety of structural analogues that might emerge from the ongoing clinical development of prolylhydroxylase inhibitors as novel lead drug candidates.

\section{Acknowledgments}

The authors acknowledge support for this study by Antidoping Switzerland (Berne), Switzerland, the Federal Ministry of the Interior of the Federal Republic of Germany, and the ManfredDonike Institute for Doping Analysis (Cologne), Germany.

\section{References}

1. Kaelin, W. G., Jr.; Ratcliffe, P. J. Oxygen Sensing by Metazoans: The Central Role of the HIF Hydroxylase Pathway. Mol. Cell. 2008, 30, 393-402.

2. Tanaka, T.; Nangaku, M. Drug Discovery for Overcoming Chronic Kidney Disease (CKD): Prolyl-Hydroxylase Inhibitors to Activate Hypoxia-Inducible Factor (HIF) as a Novel Therapeutic Approach in CKD. J. Pharmacol. Sci. 2009, 109, 24-31. 
3. Wenger, R. H. Cellular Adaptation to Hypoxia: O2-Sensing Protein Hydroxylases, Hypoxia-Inducible Transcription Factors, and O2-Regulated Gene Expression. FASEB. J. 2002, 16, 1151-1162

4. Epstein, A. C.; Gleadle, J. M.; McNeill, L. A.; Hewitson, K. S.; O’Rourke, J.; Mole, D. R.; Mukherji, M.; Metzen, E.; Wilson, M. I.; Dhanda, A.; Tian, Y. M.; Masson, N.; Hamilton, D. L.; Jaakkola, P.; Barstead, R.; Hodgkin, J. Maxwell, P. H.; Pugh, C. W.; Schofield, C. J.; Ratcliffe, P. J. C. Elegans EGL-9 and Mammalian Homologs Define a Family of Dioxygenases that Regulate HIF by Prolyl Hydroxylation. Cell 2001, 107, 43-54

5. Ivan, M. Kondo, K. Yang, H. Kim, W. Valiando, J : Ohh, M. Salic, A. Asara, J. M.; Lane, W. S.; Kaelin, W. G., Jr. HIF $\alpha$ Targeted for VHLMediated Destruction by Proline Hydroxylation: Implications for O2 Sensing. Science 2001, 292, 464-468.

6. Bruick, R. K.; McKnight, S. L. A Conserved Family of Prolyl-4-Hydroxylases that Modify HIF. Science 2001, 294, 1337-1340.

7. Bruegge, K.; Jelkmann, W.; Metzen, E. Hydroxylation of HypoxiaInducible Transcription Factors and Chemical Compounds Targeting the HIF-\&; $\alpha$ Hydroxylases. Curr. Med. Chem. 2007, 14, 1853-1862.

8. Nangaku, M.; Kojima, I.; Tanaka, T.; Ohse, T.; Kato, H.; Fujita, T. Novel Drugs and the Response to Hypoxia: HIF Stabilizers and Prolyl Hydroxylase. Recent Patents Cardiovasc. Drug Discov. 2006, 1, 129-139.

9. Warshakoon, N. C.; Wu, S.; Boyer, A.; Kawamoto, R.; Sheville, J.; Renock, S.; Xu, K.; Pokross, M.; Zhou, S.; Winter, C.; Walter, R.; Mekel, M.; Evdokimov, A. G. Structure-Based Design, Synthesis, and SAR Evaluation of a New Series of 8-Hydroxyquinolines as HIF-1alpha Prolyl Hydroxylase Inhibitors. Bioorg. Med. Chem. Lett. 2006, 16, 55175522 .

10. Thevis, M.; Kohler, M.; Schlorer, N.; Schanzer, W. Gas-Phase Reaction of Substituted Isoquinolines to Carboxylic Acids in Ion Trap and Triple Quadrupole Mass Spectrometers after Electrospray Ionization and CollisionInduced Dissociation. J. Am. Soc. Mass Spectrom. 2008, 19, 151-158.

11. Urquilla, P. Up-regulation of Endogenous EPO in Healthy Subjects by Inhibition of HIF-PH. J. Am. Soc. Nephrol. 2004, 15, 546A.

12. Günzler, V.; Muthukrishnan, E.; Neumayer, H. H.; Sacherer, K.; Schmidt, R.; Mitzner, A.; Wiecek, A.; Piecha, G.; Ignacy, W.; Scigalla, P. FG-2216 Increases Hemoglobin Concentration in Anemic Patients with Chronic Kidney Disease. J. Am. Soc. Nephrol. 2005, 16, 758A.

13. Klaus, S. J.; Langsetmo, I.; Neff, T.; Lin, A.; Liu, D. Beneficial Pharmacodynamic Effects Resulting from 'Complete Erythropoiesis' Induced by Novel HIF Prolyl Hydroxylase Inhibitors FG-2216 and FG-4592. I. Am. Soc. Nephrol. 2008, 19, 524A.

14. Inc., A. P. Adverse Event of FG-2216 for the Treatment of Anemia. www. astellas.com/en/corporate/news/pdf/080402_eg.pdf 2007, accessed 0527-2009.
15. Inc., A. P. The FDA Accepts the Complete Response for Clinical Holds of FGH-2216/FG-4592 for the Treatment of Anemia. www.astellas. com/en/corporate/news/pdf/080402_eg.pdf 2008, accessed 05-272009

16. Weisz, A.; Andrzejewski, D.; Fales, H. M.; Mandelbaum, A. Attachment of Neutrals During Tandem Mass Spectrometry of Sulfonic Acid Dyes and Intermediates in an Ion Trap. J. Mass Spectrom. 2002, 37, 1025-1033.

17. Perera, B. A.; Ince, M. P.; Talaty, E. R.; Van Stipdonk, M. J. Gas Phase Attachment of Water and Methanol to Ag(I) Complexes with $\alpha$-Amino Acids in an Ion Trap Mass Spectrometer. Rapid Commun. Mass Spectrom. 2001, 15, 615-622.

18. Kölliker, S.; Oehme, M.; Merz, L. Unusual MS ${ }^{n}$ Fragmentation Pattern of 2,4-Dinitrophenylhydrazine and its Propanone Derivative. Rapid Commun. Mass Spectrom. 2001, 15, 2117-2126.

19. Moraes, L. A.; Eberlin, M. N. Structurally Diagnostic Ion-Molecule Reactions: Acylium Ions with $\alpha-, \beta-$, and $\gamma$-Hydroxy Ketones. J. Mass Spectrom. 2002, 37, 162-168.

20. Guan, Z.; Liesch, J. M. Solvation of Acylium Fragment Ions in Electrospray Ionization Quadrupole Ion Trap and Fourier Transform Ion Cyclotron Resonance Mass Spectrometry. J. Mass Spectrom. 2001, 36, 264-276.

21. Fibrogen, E. P. 1538160 A1. European Patent Office 2005.

22. Perdew, J. P.; Burke, K.; Ernzerhof, M. Generalized Gradient Approximation Made Simple. Phys. Rev. Lett. 1996, 77, 3865-3868.

23. Weigend, F.; Häser, M.; Patzelt, H.; Ahlrichs, R. RI-MP2: Optimized Auxiliary Basis Sets and Demonstration of Efficiency. Chem. Phys. Lett. 1998, 294, 143-152.

24. Weigend, F. Accurate Coulomb-Fitting Basis Sets for $\mathrm{H}$ to Rn. Phys. Chem. Chem. Phys. 2006, 8, 1057-1065.

25. Treutler, O.; Ahlrichs, R. Efficient Molecular Numerical-Integration Schemes. J. Chem. Phys. 1995, 102, 346-354.

26. Ahlrichs, R.; Bär, M.; Häser, M.; Horn, H.; Kömel, C. Electronic Structure Calculations on Workstation Computers-the Program System TURBOMOLE. Chem. Phys. Lett. 1989, 162, 165-169.

27. Häser, M.; Ahlrichs, R. Improvements on the Direct SCF Method. J. Comput. Chem. 1989, 10, 104-111.

28. Ahlrichs; Bär, M. Baron, H.-P. Bauernschmitt, R. Böcker, S.; Ehrig, M Eichkorn, K.; Elliott, S.; Furche, F.; Haase, F.; Häser, M.; Horn, H.; Huber, C.; Huniar, U.; Kattannek, M.; Kölmel, C.; Kollwitz, M.; May, K.; Ochsenfeld, C.; Öhm, H.; Schäfer, A.; Schneider, U.; Treutler, O.; von Arnim, M. Weigend, F.; P., W.; Weiss, H. TURBOMOLE (vers. 5.9). Universität Karlsruhe 2006.

29. Cagnin, A.; Gerhard, A.; Banati, R. B. The Concept of In Vivo Imaging of Neuroinflammation with [11C](R)-PK11195 PET. Ernst Schering Res Found Workshop 2002, 179-191. 